\title{
El Conocimiento, la Tecnología y la Educación Virtual
}

Por: Benjamín Losada Posada ${ }^{1}$

Guillermo Jerez Cortes ${ }^{2}$

Junio , 2013

Es preciso hacer referencia al conocimiento filosófico y científico pues si bien son esencialmente distintos lo son también complementarios e indivisibles. El filosófico y el científico están dirigidos a la totalidad de las cosas donde impera la diversidad, no solamente en el sentido objetivo sino también en el subjetivo, el conocimiento científico está orientado hacia la realidad, una realidad absolutamente cambiante como la de hoy que obliga al ciber-ciudadano a una educación virtual continuada, que desborda conocimiento y pensamiento.

Desde la filosofía se aborda la teoría del conocimiento y la teoría del conocimiento científico. Tradicionalmente a la filosofía se le estudia desde tres partes: teoría de la ciencia, teoría de los valores y concepción del universo. Ahora bien, la teoría de la ciencia también se subdivide en formal y material, la primera se denomina lógica, y la segunda teoría del conocimiento, la cual se dirige a los supuestos materiales más generales del conocimiento científico. Si bien la lógica pregunta por la correlación formal del pensamiento y la concordancia consigo mismo, bajo sus propias formas y leyes, la teoría del conocimiento pregunta por la verdad del pensamiento en la concordancia con el objeto.

El denominado pensamiento post modernista, se basan en los siguientes postulados: promueve el pluralismo, la diversidad y busca el interés de los otros, es aquí donde la red internet-tecnología-virtualidad van de la mano para revolucionar el conocimiento con el pensamiento.

El argumento post modernista respecto al lenguaje dice que el lenguaje moldea el pensamiento, y no puede haber ningún pensamiento sin lenguaje, por lo tanto el lenguaje crea literalmente la verdad, el giro lingüístico; y frente a la verdad argumenta que es cuestión de perspectiva o contexto, (más que ser algo universal), por lo tanto, no tenemos acceso a la realidad, únicamente a lo que nos parece.
Para la tecnología, el enfoque posmoderno es fundamental, pues el pluralismo y la diversidad son partes que confluyen en las Tecnologías de la Información y las Telecomunicaciones (TICs). Con el avance en las comunicaciones, la informática, y la información acompañadas de un irremisible paso a la educación virtual continuada para "mantenerse vigente como ciberciudadano" se evidencia lo enunciado anteriormente.

Se pasa del modelo de producción al modelo del consumo desenfrenado real o inclusive virtual. La mezcla en el consumo compulsivo, del valor de la naturaleza y la defensa del medio ambiente; el centro del poder se da en los medios masivos y la industria de consumo masivo.

La producción de excesiva información, mediante los medios de comunicación convertidos en trasmisores de la verdad, implica que al no aparecer en estos nada existe para la sociedad. El dilema de hoy inmerso entre redes sociales Youtube, Facebook, Twitter) y portales temáticos desborda a los medios tradicionales, al punto que los nuevos medios traen y llevan la nueva educación, o educación virtual continuada.

La pérdida de la intimidad y la aparición de redes sociales mediante las cuales se convierte en espectáculo la vida de los demás; se desmitifican los líderes; se cuestiona la religión entre otros.

"La posmodernidad en realidad se presenta como anti modernidad. Él define a los posmodernistas como jóvenes conservadores' $y$ dice que estos recuperan la experiencia básica de la modernidad estética; reclaman como suyas las confesiones de algo que es subjetivo, liberado de las obligaciones del trabajo y la utilidad y con esta experiencia dan un paso fuera del mundo moderno. Este autor defendía la diversidad de las diferentes culturas bajo el primado de los derechos humanos como base normativa de "una vida libre de dominación". Ello supone 
llevar a cabo una segunda Ilustración de la modernidad, que corrija sus fallos, al tiempo que preserve sus logros ciudadanos y democráticos." (Habermas, 1989, p. 143)

En cuanto a la formación de la sociedad del Información y los medios masivos de comunicación como eje central de la pos modernidad citamos dos definiciones: la de Huyssen (1989), "defiende que la cultura posmoderna debería ser captada en sus logros y sus pérdidas, en sus promesas y perversiones e intenta defender con sus obras (Dialécta Escondida, Guía de la Posmodernidad...) que si las vanguardias intentaron cambiar el mundo, más lo hizo la tecnología, la industria cultural.

El surgimiento de la cultura posmoderna se debió a las nuevas tecnologías que se apoyan en el lenguaje: los medios de comunicación y la cultura de la imagen. Según Lyotard, las tecnologías comunicativas han producido una sociedad de la información." y la otra Vattimo (1990), "la posmodernidad, una especie de 'babel informativa', donde la comunicación y los medios adquieren un carácter central. Las ideas de la posmodernidad y del pensamiento débil están estrechamente relacionadas con el desarrollo del escenario multimedia, con la toma de posición mediática en el nuevo esquema de valores y relaciones. Con base en el trabajo de ese autor se han realizado múltiples trabajos en la teoría de los medios de comunicación en la posmodernidad.", (G.Vattino, 1990, p. 129).

Es claro ver las grandes simientes de los cambios tecnológicos a los cuales se avoca el siglo XXI con la WEB 3.0 el fortalecimiento de los servicios recurrentes en basados tecnologías convergentes que han llevado a profundos cambios en los modelos de vida.

A continuación se relacionan de manera cronológica los cambios sufridos en esta materia:

A comienzos del siglo XX se dio origen a esquemas de vida orientados por el Marketing Moderno, donde la empresa se orientaba a la producción. Para la mitad del siglo, el marketing se transforma y toma el rumbo a "la orientación a las ventas". En 1970 se pasa a la "orientación a los mercados", dando origen al marketing masivo de nichos y segmentos. La promoción se da mediante los medios masivos.

A finales del siglo XX se da la orientación al marketing personal y la Fidelización de los clientes, las TICs facilitan la implementación de este modelos como el de Don Pepers "Enterprise One-to-One" comercializar productos sobre una base individual y no hay que pensar en términos agregados, nichos o segmentos de mercado, la publicidad se vuelve interactiva, todo se planifica todo se ejecuta todo se controla, todo se mide.

Se permite la construcción de grandes bases de datos que facilitan la relación para construir los perfiles individuales y esto origina conocimiento (conocimiento complejo donde la precisión de los datos y su generalización, contrastan a su vez con las diferencias individuales, la singularidad.....en torno a intereses globales de sostenibilidad y otros.

La concepción del pensamiento moderno de la disociación, "Toma distancia del sentido que le confiere Martín Heidegger, para quien "deconstrucción" equivale a "destrucción" y del que le atribuye Sigmund Freud que la equipara a "disociación", (Habermas, Borradori, \& Derrida, 2004) de las ciencias en conocimientos específicos y especializados.

Sin duda de utilidad es la presentación de tesis y autores lo que permite formarse una idea panorámica del desarrollo del pensamiento contemporáneo a partir del post estructuralismo francés, F. Sasurre, C. Lévi Strauss, R. Barthes, M. Foucault, G. Deleuze, Baudrillart, entre otros, y del movimiento llamado "deconstruccionista", con Derrida a la cabeza, pasando luego por la derecha neoliberal de Fukuyama, Alvin Toffler, Samuel Huntington y John Negroponte, para nombrar algunos de los autores.

Se sigue con los denominados libertarios con John Rawls, Alasdair Macintyre y Amitai Etzioni y muchos otros más postcoloniales: Inclusive el caos y lo holístico (ver tabla No. 1) están en controversia con el pasamiento pos modernista.

"La condición post moderna de la que nos habla Lyotard, es la incredulidad respecto de los relatos y meta relatos, la deslegitimación del discurso especulativo y emancipatorio, y, como consecuencia, la crisis de la metafísica.".

Los pensadores más destacados de las corrientes posmodernas son Gilles Deleuze, Jean Baudrillard, JeanFrançois Lyotard, Jacques Lacan, Michel Foucault, Gianni Vattimo, Jacques Derrida, Gilles Lipovetsky, Slavoj Zizek, Alain Badiou, Durkheim (padre de la teoría Funcionalista), Bernstein, Bourdieu, entre otros. 
ISSN-2248-736 * Número 3 * Revista Facta Non Verba

Tabla No. 1 Mapa del Pensamiento Contemporáneo

\begin{tabular}{|c|c|c|c|}
\hline Autor & Obras más representativas & Variedades & Concepto heurístico \\
\hline J.Lyotard & "La Condición Postmoderna" & Clásico & Metarrelato \\
\hline J.Derrida & "Escritura y Diferencia" & & Diferencia Deconstrucción \\
\hline F. Fukuyama & "El fin de la Historia" & Neoliberalismo & Mercado \\
\hline S. Huntington & "Choque de civilizaciones" & Geo - culturalismo & Geocultura \\
\hline R. Putnam & "Declive del Capital Social" & $\begin{array}{l}\text { Neo -institucionalis- } \\
\text { mo }\end{array}$ & Capital social \\
\hline J. Butler & "Género en Disputa" & Teorías Queer & Performance \\
\hline T. Negri & "Imperio" & Marxismo Abierto & Multitud \\
\hline P. Sloterdijk & "Crítica de la razón cínica" & Cinismo ilustrado & Cinismo \\
\hline N. G. Canclini & "Culturas Híbridas" & $\begin{array}{l}\text { Estudios ulturales, } \\
\text { Culturas, Híbridas }\end{array}$ & Media Hybris \\
\hline Edward Said & $\begin{array}{c}\text { “Orientalismo", ¿¿Pueden hablar } \\
\text { los Subalternos?" }\end{array}$ & Estudios Subalternos & Poder Narrativo \\
\hline Gayatri Spivak & "El lugar de la Cultura" & Post - & Construcción del Otro \\
\hline Homi Bahba & & occidentalismo & Imaginarios \\
\hline W. Mignolo & $\begin{array}{l}\text { "Posoccidentalismo: el argumen- } \\
\text { to desde América Latina" }\end{array}$ & & Colonialidad \\
\hline Ilya Prigogine & "El Fin de la Certidumbre" & Caos determinista & Disipación \\
\hline Benoit Mandel Broot & "Geometría Fractal" & Caología & Fractal \\
\hline Briggs y Peat & "Espejo y Reflejo" & & Autopoiesis \\
\hline Edgard Morin & $\begin{array}{l}\text { "Introducción a la Teoría de la } \\
\text { complejidad" }\end{array}$ & $\begin{array}{l}\text { Teoría de la Comple- } \\
\text { jidad }\end{array}$ & Holograma \\
\hline Ken Wilber & "Breve Historia de las Cosas". & $\begin{array}{l}\text { Pensamiento de se- } \\
\text { gundo grado }\end{array}$ & $\begin{array}{l}\text { Meme, Holon, Holoarquías, } \\
\text { Cuadrante No dual (advaita) }\end{array}$ \\
\hline
\end{tabular}

El filósofo italiano Gianni Vattimo define el pensamiento posmoderno de la siguiente manera: "en él lo importante no son los hechos sino sus interpretaciones. Así como el tiempo depende de la posición relativa del observador, la certeza de un hecho no es más que eso, una verdad relativamente interpretada y por lo mismo, incierta". de un sujeto fuerte al estilo de Hegel, Kant e incluso Marx y el planteamiento del tiempo lineal como el de Leibniz son puestos en tela de juicio. Dos características fundamentales del pos modernismo se encuentran en la transversalidad y transdisciplinariedad del conocimiento elemento fundamental en la construcción de las ciencias computacionales, informáticas y de comunicación que permiten la convergencia en TICs y la generación 
de nuevas tecnologías que determinan un ciber-ciudadano capacitado, competente para si mismo y en si mismo mediante la educación virtual continuada entroniza ahora también casi de manera mágica por Youtube.

Pensando en esa magia nos internamos a continuación en la importancia del método, así como la aplicación de método científico desde la perspectiva clásica, dada su vigencia en medio de la ruptura de todo tipo de paradigmas.

\subsection{La importancia del método}

Desde el siglo XVII hasta finales del siglo XIX la cuestión principal en epistemología se contrastó la razón contra el sentido de percepción como medio para adquirir el conocimiento.

Para los racionalistas, más destacados como el francés René Descartes, el holandés Baruch Spinoza y el alemán, Gottfried Wilhelm Leibniz, la principal fuente y prueba final del conocimiento era el razonamiento deductivo basado en principios evidentes o axiomas.

Para los empiristas, empezando por los filósofos ingleses Francis Bacon y John Locke, la fuente principal y prueba última del conocimiento era la percepción.

Como ocurre con casi todos los temas, en el caso de la definición de ciencia nos encontramos con una gran variedad de pareceres: desde las que afirman que se trata básicamente de un método de investigación, hasta las que opinan que son los resultados de la investigación en una zona determinada; es decir, unas hacen hincapié en el método de consecución de los conocimientos, mientras que otras se concentran en los conocimientos producidos por el método.

En este sentido, quizás la mejor definición de ciencia que contiene estos dos aspectos a la vez sea la que ofrece Bunge (1980), cuando afirma que una ciencia es una disciplina que utiliza el método científico con la finalidad de hallar estructuras generales (leyes), distinguiendo entre el trabajo (investigación) y su producto final (conocimiento), lo cual coincide plenamente con el planteamiento de Kerlinger (1982), cuando opina que sobre ciencia se pueden considerar dos puntos de vista: uno estático, en cuanto constituye un corpus organizado y sistematizado de conocimientos, en cuyo caso la equivalencia con el término teoría es evidente; y otro, dinámico, en cuanto considera la ciencia como una actividad de producción de conocimientos sistemáticos, conexos y fundamentados, entonces puede hablarse de investigación científica.

Respecto a las características que se suelen asignar a la ciencia, queda claro que debe ser objetiva, contrastable, sistemática, metódica y comunicable.

Ahora bien, teniendo en cuenta que el conocimiento científico no es infalible, estaremos de acuerdo con Popper (1977) cuando afirma que la objetividad hace de todo enunciado científico algo provisional para siempre, así que no acepta como cien $\neg$ tífico ninguno que no sea contrastable, proponiendo como criterio lo falso y no la verificabilidad.

De todas formas, cualquiera que sea la definición o enfoque adoptados, estaremos de acuerdo con Manheim (1982) en que existe casi la unanimidad de que se deben dar tres objetivos en la ciencia: primero, la descripción, que responde a la pregunta ¿qué?; ya que, como punto de partida, debemos saber de qué estamos hablando. La explicación es el segundo objetivo, que responde a la pregunta ¿Por qué? y nos dice cómo se producen las cosas y los acontecimientos, qué los causa y cuáles son las leyes que determinan su aparición. Y el tercero, es la predicción, ¿Para qué?, qué deducciones extraer de los hechos o leyes en términos de probabilidad.

Estas observaciones nos llevan a pensar que ciencia es un conjunto de teorías y sus correspon $\neg$ dien $\neg$ tes procesos de investigación que describen, explican y predicen los fenómenos de una determina $\neg$ da parcela de la realidad.

Aunque puede precisarse la diversidad de métodos que se sitúan con respecto a los fundamentos epistemológicos, propios de la ciencia social, se destaca para los propósitos de presente escrito el aporte de René Descartes con la concepción del método científico (1596-1650) como filósofo y matemático francés, autor del "Discurso del Método, para dirigir bien la razón y buscar la verdad en las ciencias" (1637, en francés), obra capital y que reconocidamente marca el inicio de la filosofía "moderna". 3

El gran aporte de René Descartes en su obra el Discurso 
ISSN-2248-736 * Número 3 * Revista Facta Non Verba

del Método (1637), expresa, la no autocomplacencia, ni la aceptación ciega de los conocimientos de otros, insiste en la búsqueda constante del saber, la esencia del ser humano, el pensamiento y la razón sintetizado en: $E l$ Método Cientifico.

René Descartes en su obra el "Discurso del método" asumió varios riesgos gracias a que en 1630, se presentaban algunos antecedentes tales como el de Galileo Galilei quien había sido condenado por la inquisición, cuando hace su aseveración de que "la tierra gira alrededor del sol", esto obligó a Descartes a implementar una estrategia la cual consistía en retardar la publicación por espacio de 7 años y durante estos se propuso efectuar un lobby para la consecución de los permisos, sin embargo la obra de Galilei fue censurada y tan solo 50 años después de su muerte es publicada. ${ }^{4}$

Descartes es reconocido como ejemplo del racionalismo, sostenía que los animales podrían ser totalmente imitados por autómatas. Su libro "El discurso del Método" es fundamental por dos grandes aportes: la importancia que le asigna a la razón (pienso, luego existo. Cogito, ergo sum) y el método de análisis.

De las frases más celebres de toda la filosofía es la enunciada por Descartes, la cual se encuentra plasmada en su libro. "Pienso, luego existo". El mismo Descartes dice: "Sólo nuestros pensamientos están enteramente en nuestro poder, de manera que, después de haber obrado lo mejor que hemos podido, en lo tocante a las cosas exteriores, lo que no logramos es absolutamente imposible para nosotros". Manifiesta que después de grandes meditaciones la única verdad superior que encontró es que "Pensamos", las emociones, las imágenes externas, los sueños, las sensaciones del cuerpo no son de fiar, (Vattimo, 1990). El asigna el pensamiento en un lugar etéreo y fuera del cuerpo, logrando separar lo físico de lo emocional, su aporte a la planificación se da mediante la delimitación en dos grandes grupos: la parte "operativa" y la "planeación".

El gran aporte de su obra es: el método-de análisis - el cual efectúa mediante cuatro fases o reglas que deben seguirse en búsqueda de la verdad en las ciencias, que permiten avanzar en la estructuración y profundización del conocimiento; la primera, "Toda afirmación debe ser clara, distinta y acompañarse de evidencia. De lo contrario es falsa" o No aceptar nada como cierto, es decir, no aceptar sino aquello incapaz de hacer dudar a nuestro espíritu: (La duda). La segunda, "Todo problema se descompone en tantas partes como sea necesario hasta llegar a las naturalezas simples —mínima expresión que se advierte por intuición-. ", Dividir todo problema examinado en tantas parcelas o partes como fuese posible y necesario para mejor entender la cuestión: (Análisis). La tercera, "Buscar las soluciones, o enunciados, yendo desde lo fácil a lo dificil, a partir de esas naturalezas simples." Ordenando todo pensamiento y dando comienzo de lo más sencillo hasta lo más complejo: (Ordenar). La cuarta, "Enumerar y revisar. Consiste en evitar los errores producto de descuidos o datos no confirmados", Hacer siempre enumeraciones tan complejas y revisiones tan generales hasta estar seguro de no omitir nada: (Enumerar), los cuales, se presentan a continuación con el ánimo de contextualizar al lector.

\section{* "Toda afirmación debe ser clara, distinta y acom- pañarse de evidencia. De lo contrario es falsa".}

En cuanto a la búsqueda de las verdades superiores, punto en el cual Descartes coincide con los Sofistas (clásicos griegos), puesto que se tomaba una posición en la discusión de un tema y de salir victorioso, posteriormente, se optaba por otra posición contraria frente al mismo tema y se volvía a ganar.

Descartes, al estudiar a los filósofos griegos clásicos como: Pitágoras, Sócrates, Paltón, recibe una gran influencia en su pensamiento, puede observarse que de Sócrates (469-399 a.C.), la duda, la cual había descubierto una verdad racional superior "sólo sé que nada sé". De Platón, la aplicación de la lógi$c a$, pues en la su disertación de la "Apología de Sócrates”, como su aplicación lógica — en el sentido de hacer uso de la lógica matemática mediante su postulado: "si $A$ es cierto y $B$ es cierto entonces $C$ es cierto", postulado que estaba dirigido a demostrar, a las personas que se atrevían a dialogar con él, que eran ignorantes y cuando menos, poco virtuosas, evidentemente, sus interlocutores quedaban muy molestos.

Dos ejemplos de Platón, evidencian lo aseverado en el párrafo anterior, el primero sobre las palabras de Sócrates “...Examinando, pues, a mi hombre - no es necesario dar su nombre; era uno de nuestros políticos-tuve, al 
examinarlo, señores atenienses, una impresión más o menos como ésta. Conversando con él, me pareció que muchos otros lo creían sabio, y especialmente se creía sabio él; pero que no lo era. Seguidamente traté de demostrarle que él se creía sabio sin serlo. De aquí vino que quedé enemistado con él y con muchos de los presentes; mientras iba pensando que yo era más sabio que él. Bien puede ser que ninguno de nosotros dos sepa nada de bello ni de bueno; pero este cree saber algo y no lo sabe, mientras yo no sé ni creo saberlo tampoco. Parece, entonces, que en cierta pequeña medida soy más sabio que él, pues, no sé ni creo saber". El segundo ejemplo, ilustra el uso intensivo de la lógica cuando Sócrates da la respuesta a la acusación de la mala influencia en los jóvenes. Dice: “...pero, o no los corrompo, o, si los corrompo, es involuntariamente, de modo que en ambos casos tú mientes. Si los corrompo involuntariamente, ...". ${ }^{5}$ A los ciudadanos de la época les molestaba la insistencia en sus verdades. Solamente con Emmanuel Kant (1724-1804) vino a ser de aceptación general que los principios éticos debían tener validez universal.

\section{* "Todoproblemasedescomponeen tantaspartescomo sea necesario hasta llegar a las naturalezas simples - mínima expresión que se advierte por intuición-."}

El análisis se orienta al interior del objeto de estudio, la técnica consiste en dividirlo en sus partes, la aplicación de esta técnica a los sistemas no mecánicos es muy limitada, y para obtener el conocimiento en algunos casos hay que sacrificar el objeto de estudio: una persona, una organización, un juego.

\section{* "Buscar las soluciones, o enunciados, yendo desde lo fácil a lo difícil, a partir de esas naturalezas simples."}

La deducción es una técnica que consiste en reagrupar de acuerdo con la naturaleza simple para realizar conclusiones generales. Pero presenta dificultad y se convierte en algunos casos peligrosos al momento de realizar conclusiones cuando de sistemas sociales se refiere.

En la actualidad, la aplicación de análisis y deducción, son utilizadas en los desarrollos de programación en la ciencias computacionales, el ejemplo que se analiza es una solución administrativa, caso aplicativo de nómina; en su análisis se observa que está compuesto de varios pequeños programas y tienen muchas similitudes entre sí: Ingresar datos, modificación, consulta, obtención de reportes, así se puede definir características para cada uno de esto programas (deducción), que permite la programación orientada a objetos para cada uno de los casos.

Los resultados dependerán del tipo de sistema en el cual se esté implementando en los sistemas estructurados, los resultados son maravillosos, pero no se podría decir lo mismo cuando de sistemas sociales se trata, ya que el grado de incertidumbre, autonomía y viabilidad conllevan a aplicar la técnica de síntesis.

\section{* "Enumerar y revisar. Consiste en evitar los errores producto de descuidos o datos no confirmados".}

La responsabilidad personal, debe verificar y asegurar que la aplicación de los métodos de síntesis y análisis tenga una validez universal.

¿Qué efectos tuvo el método de Descartes? Muchos y fundamentales. La naciente era industrial lo hizo suyo y en los siguientes tres siglos el método fue aplicado a casi todo nuestro entorno, comenzando por la organización del colegio y la universidad (División del "problema" en múltiples cursos), siguiendo por el diseño de los Estados, la estructura de las organizaciones y... los estilos tradicionales de planificación. Sólo en carácter de muestra, veamos las aplicaciones de dos autores clásicos que a su vez tuvieron gran influencia Adam Smith y Frederick Winslow Taylor.

\subsection{Aplicación del Método Científico (desde la pers- pectiva clásica)}

Mediante un ejemplo cotidiano, se presenta la aplicación del Método Científico, se explica las cuatro fases del mismo:

Un individuo se dispone ir al trabajo en su vehículo, al momento de accionar la llave, el vehículo no se pone en funcionamiento, para lo cual, gira la llave durante varias veces sin obtener respuesta, verifica que el sistema eléctrico actúe en el momento de la apertura para verificar la activación de los indicadores en el tablero, repite la acción y no se pone en funcionamiento, verifica la cantidad de combustible, la conexión de la batería, sospecha que se activó un mecanismo de seguridad mediante 
ISSN-2248-736 * Número 3 * Revista Facta Non Verba

la alarma, activay desactiva la alarma con el procedimiento descrito para tal fin y vuelve a intentar la acción inicial, el resultado, el vehículo se pone en funcionamiento.

La descripción del ejemplo, es una acción de recurrencia diaria en el transcurrir cotidiano pero tiene un comportamiento isomorfo del método científico:

Observación: El vehículo no se pone en funcionamiento.

Hipótesis: Posiblemente falta combustible o presenta un daño eléctrico.

Predicción: Si la hipótesis es cierta debo verificar mediante el indicador.

Verificación: Realización de la prueba, el vehículo no se puso en funcionamiento, no se confirman mis predicciones ("falsificación").

Segunda hipótesis

Observación: El vehículo no se pone en funcionamiento

Hipótesis: Presenta un daño eléctrico.

Predicción: Al revisar las conexiones de la batería y verificación de los instrumentos, tiene que entrar el vehículo en funcionamiento.

Verificación: Una vez verificadas las condiciones eléctricas, sigue el vehículo sin funcionar.

Se acepta como teoría provisional que el daño en el arranque del vehículo se debe a la falla en el sistema eléctrico, planteando varias hipostasis adicionales, se acepta que la activación de seguridad de la alarma es la que ocasionó la no puesta en funcionamiento del vehículo, pues la razón de hipótesis se debe a que es la más simple de contrastar.

La explicación de la segunda hipótesis se convierte en explícita pues es lo que siempre se hace de forma inconsciente.

La diferencia entre el método científico y la vida cotidiana radica en que el método científico es más sistemático y explícito que la vida cotidiana: para método científico es fundamental que no se pierda accidentalmente información importante y la réplica de los pasos por otras personas que los conduzcan a la obtención de los mismos resultados.

Ejemplo de ello es cuando se hace una aseveración como la siguiente: "La máquina podadora esta en el jardín", pero no la está viendo directamente, lo que se constituye en una teoría pero no en un hecho, así la evidencia sea abrumadora.

Se encuentran totalmente equivocadas aquellas personas que en algunas ocasiones y despectivamente dan por aceptada que una explicación comúnmente aprobada por la comunidad científica, es sólo "una teoría científica". Cuando una explicación se considera una teoría científica es porque es más mucho más que una hipótesis y está sólidamente contrastada con base en el método científico.

Sobre la teoría del conocimiento en la filosofía de los clásicos se efectúan múltiples reflexiones epistemológicas especialmente en Platón y Aristóteles. La teoría del conocimiento como disciplina autónoma aparece en la edad moderna con el filósofo inglés John Locke, con su obra "Ensayo sobre el entendimiento humano", con otras obras que se presentan en el siguiente resumen, tabla No 2:

\begin{tabular}{|l|l|}
\hline \multicolumn{1}{|c|}{ Autor } & \multicolumn{1}{|c|}{ Obra } \\
\hline Gottfried Wilhelm Leibniz & $\begin{array}{l}\text { * Nuevos ensayos sobre el entendimiento } \\
\text { humano }\end{array}$ \\
\cline { 2 - 2 } & * Método y realidad en la filosofía racionalista \\
\hline George Berkeley & *Tratado de los principios del conocimiento \\
humano
\end{tabular}

Tabla No. 2 Trabajos relacionados con la Teoría del conocimiento 
La teoría del conocimiento aflora por primera vez bajo el títulos "Teoría de la ciencia", lo que se prestó para una confusión entre la teoría del conocimiento y la metafísica como lo presentaron en su trabajos Schilling y Hegel (Hessen, 1970), lo mismo Schopenhauer y Hartmann, aunque el Neokantismo también contribuye con su aporte entre la separación de los problemas epistemológicos y los problemas metafísicos.

Si bien las posibilidades del conocimiento pueden tomar diferentes enfoques filosóficos como: el dogmatismo, el escepticismo, el subjetivismo, el realismo, el pragmatismo, y el criticismo, el origen del conocimiento también puede basarse en, el realismo, el empirismo, el intelectualismo y el apriorismo.

Otros autores entre ellos, Jean Piaget, explica las formas del pensamiento humano y el conocimiento objetivo de la realidad, interesándose en el proceso, desarrollo cualitativo, el progreso de maduración del pensamiento y las estructuras intelectuales .La teoría de Piaget se sustenta en los siguientes supuestos básicos:

"El crecimiento biológico está en el origen de todos los procesos mentales. Las experiencias que tienen los infantes promueven su desarrollo cognitivo, por lo que se les debe proporcionar un ambiente rico en experiencias, adaptado a su grado de madurez, Cada etapa implica una repetición de procesos del nivel anterior, bajo una diferente forma de organización, Las diferencias en las pautas de organización dan lugar a una jerarquía de experiencias y acciones".

De acuerdo con la teoría expuesta por Piaget en el modelo activista y la maduración del pensamiento en cada etapa esta relacionados teorías pedagógicas de María Montessori, Herbat, John, Claparede Dewey, Decroly, Ferrier, Freinet, y Vigotsky los cuales proponen nuevas metas educativas, centradas en las habilidades donde el alumno es el eje central del proceso al cual hay que orientarlo como un adulto.

Según el existencialista, Martin Heidegger, construimos un camino cuando preguntamos por la técnica, la cual la define como:

"Todo el mundo conoce los dos enunciados que contestan anuestrapregunta.Elunodice: latécnicaesunmediopara unos fines. El otro dice: la técnica es un hacer del hombre. Las dos definiciones de la técnica se "copertenecen", por cuanto poner fines, crear y usar medios para ellos es un hacer del hombre. La técnica pertenece el fabricar y usar útiles, aparatos y máquinas; pertenece esto mismo que se ha elaborado y se ha usado, como también pertenecen a la técnica, las necesidades y los fines a los que sirven. Ella misma es una instalación, dicho en latín: un "instrumentum." (Heidegger, 1994)

Heidegger, hace toda una exposición existencialista de la técnica, partiendo de la existencia humana cuyo rasgo fundamental se encuentra centrado en el "SER EN EL MUNDO", insertando cosas objetivas.

De acuerdo con Aristóteles podemos inducir que en el ejercicio productivo dentro de las organizaciones modernas reflejan los niveles de conocimiento, pero en la clasificación del conocimiento, Aristóteles no subordinó la ética, sino que al interior de las organizaciones se da el proceso de lo bueno y lo malo de las acciones de cada trabajador traducidas como ética social.

La ética se convierte en sí misma en un bien para el ser y el cual se orienta al bien (lo que se constituye en un bien en sí y un bien en la organización, aun cuando en principio pareciere redundante). Por lo tanto, todo el conocimiento según Aristóteles procede de la experiencia, para. "Platón, inicia el debate entre el empirismo y el racionalismo. Sostenía que se podía dar explicación verdadera de la realidad sin la experimentación. A lo cual Aristóteles arremetió: "No existe ninguna posibilidad de acercarse a la verdad de lo real sin la mediación de los sentidos". Es decir, sin la experimentación. No basta la explicación, solamente desde el acto de la razón.

Este debate sigue aún vigente entre la filosofía moderna. De él surgieron las corrientes racionalistas de Descartes, que retomaron a Platón y de los empiristas ingleses, Locke y Hume, que retomaron a Aristóteles.

Sin embargo, el concepto de conocimiento no se agotó en esta discusión. Surgieron preguntas adicionales que no podían explicarse en él.

¿Quién es Dios?: Se preguntaron los teólogos San Agustín y Santo Tomás.

¿Qué es el mundo y el universo?: Se preguntaron los naturalistas, ecologistas y evolucionistas: Copérnico, Galileo, Newton, Darwin.

¿Qué es el hombre? Se preguntaron los filósofos, sociólogos, 
ISSN-2248-736 * Número 3 * Revista Facta Non Verba

psicólogos, historiadores, como Kant, Conte, Nitche, Marx, Froid, entre otros.

Estas preguntas, abrirían infinidad de corrientes explicativas del conocimiento: desde el escepticismo extremo, hasta el dogmatismo moderno; desde el idealismo hasta el materialismo; desde el positivismo hasta la fenomenología, desde el romanticismo hasta el existencialismo.

Todas estas visiones justificadas desde su conocimiento, en definitiva justificadas desde su noción de verdad. Por tanto, lo que el conocimiento humano ha buscado a través de su historia ha sido realmente la verdad de las cosas y la verdad de las acciones. En síntesis, entre más nos acercamos a la verdad, más conocimiento tenemos".

Pero todo esto se centra en ¿Qué es la verdad?, la epistemología da una explicación, porque cada línea de pensamiento sustenta su concepto en la verdad, pasando desde el absolutismo hasta el relativismo: "Desde la innegable realidad de la muerte, hasta la sospecha misma de la vida".

La más reciente definición de la verdad estriba entre la conciliación de las diferentes argumentaciones la cual se ha denominado, "Creencia verdadera justificada" (Grayling, 1998; Torralba, 2005). Entonces se "explica la creencia en una cosa o acción, con indicios de verdad".

Así como se ha tenido cuenta el aporte "El método-de análisis" de René Descartes, también, las definiciones de Aristóteles, ofrecen la clasificación del conocimiento en cinco niveles, lo que resulta de utilidad, para la exposición del presente texto.

Si bien en las obras Metafísica, Ética a Nicómaco, tópicos, de Aristóteles se encuentran las características básicas de la teoría del conocimiento, elaborada, bajo los estudios de la demostración, el análisis, y el entorno de las características de la ciencia y sus divisiones, como lo es el conocimiento sensible, el cual se deriva directamente de la sensación; el basado en la experiencia, el cual se da mediante la actividad de entendimiento permite conocer el por qué y la causa de los objetos,

Dentro de la metafísica existen tres tipos de saberes, el práctico, contemplativo, y productivo, este último es el que tieneque vercon el sabertécnico, yelprácticatieneque con la capacidad de ordenar racionalmente la conducta.
*Científico (Episteme): Consiste en la explicación teórica de las cosas o de las acciones. Fundamentalmente procura dar una explicación de la realidad basado en la verdad donde pone en esencia la realidad es decir su naturaleza.

La verdad, se valida en la comprobación empírica y a su vez es la fase probatoria de la ciencias naturales. Lo que no es comprobable empíricamente se eleva a la categoría de metafísica.

El método universal se conforma por la sumatoria de teorías explicativas sobre un tema específico, la compresión, para las ciencias sociales y la comprobación para las ciencias naturales.

Los objetos de estudio formales como la economía, la equidad, la psicología, el comportamiento humano, la filosofía, el pensamiento, la justicia, lo justo, la epistemología, el conocimiento, en cuanto al objeto material tienen en común el hombre.

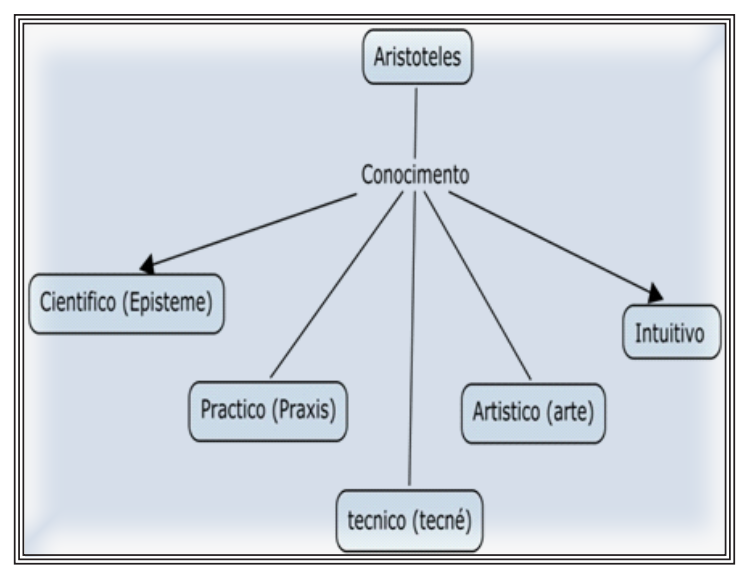

Por su parte, las ciencias naturales, formulan leyes naturales y el objeto material común, el universo.

En la búsqueda del conocimiento se desarrollaron teorías que dieron origen a los hábitos investigativos, los sujetos raros y especiales fueron aislados de las actividades normales de la sociedad y se categorizaron como científicos, respecto a la organización.

El conocimiento teórico puede ser suministrado también por un proveedor externo (Sveiby, Linard, \& Dvorsky, 2002; Medina, González, \& Falcón, 2007).

Los activos tradicionalmente se han dividido en tangible e intangibles. Los tangibles como el capital físico 
y financiero), que han sido los activos más preciados, son desplazados gradualmente (desde finales del siglo XX), por los activos intangibles tales como aprendizaje organizativo, gestión del conocimiento íntimamente relacionado con nuestro tema de estudio de la educación virtual continuada así como la medición de capital intelectual).

Este conocimiento intangible (tal como puede ser definido en derecho y también en ciencias económicas) se torna en virtual para la aparición de un nuevo ser o ciber- ciudadano que están inmerso o emerge de las redes sociales que son también las redes del conocimiento.

A su vez, este conocimiento esta compuesto por varios factores: la dimensión cultural de la organización, las políticas, los principios, los valores, la misión, la visión el saber hacer (know how), patentes, manuales de funciones y procedimientos, los estilos gerenciales y finalmente el modelo administrativo con que cuenten estas, el capital intelectual organizativo es el eje central de la estrategia para el logro y sostenibilidad de una ventaja competitiva, ya que como lo enuncia (Drucker, 1992) "el conocimiento organizativo se ha convertido en un recurso", y para ser estratégico deberá cumplir con lo siguiente:

1) No comerciable, desarrollos acumulados en la empresa, 2) Fuerte carácter tácito y complejidad social, 3) Surge a partir de las habilidades y aprendizaje organizativo, 4) Es inmóvil y está vinculado a la empresa, y 5) Su desarrollo es "dependiente de la senda", es decir, depende de los niveles de aprendizaje, inversión, stocks de activos y actividades de desarrollo previas.

El conocimiento práctico, está dado por lo que se aprende con la experiencia, en lo que respecta con la transmisión de este conocimiento entre un sujeto a otro, no requiere de una explicación teórica, en la realidad se hace mediante la correspondencia biunívoca entre la práctica y la teoría. Por ejemplo, leer un manual de cómo se repara un motor de combustión interna, no lo faculta para que ejecute la acción, es necesario elaborar la práctica donde adquiere la destreza la cual se debe desarrollar bajo las pautas teóricas.

La dependencia del conocimiento y la interrelación son propias de las organizaciones modernas, se le determina como conocimiento tácito y conocimiento explícito. Más adelante se retomarán estos conceptos y su aplicación.
Este conocimiento práctico dentro de las organizaciones lo realizan los empleados en el puesto de trabajo de acuerdo con el manual de funciones y procedimientos, y la valoración del trabajo está dada por la productividad.

Hay que diferenciar de manera clara entre la praxis y la práctica, pues, la praxis es el proceso por el cual una teoría o lección se convierte en parte de la experiencia vivida. Mientras que una lección es solamente absorbida a nivel intelectual en un aula, las ideas son probadas y experimentadas en el mundo real, seguidas de una contemplación reflexiva.

De esta manera, los conceptos abstractos se conectan con la realidad vivida.

La praxis es usada por educadores para describir un paisaje recurrente a través de un proceso cíclico de aprendizaje experimental, en tanto que la práctica, es la situación de aprendizaje en la cual un ensayo sigue al otro con o sin período de descanso alguno, utilizando un método para extinguir hábitos y por el cual se repiten en forma consciente y deliberada las tendencia erróneas asociadas a dichos hábitos.

*El conocimiento técnico (Tecné), se muestra mediante la investigación continua que da como resultado la adaptación en cuanto a la producción y optimización contante de los recursos para mejorar el talento humano. Este conocimiento se expresa en las organizaciones mediante las herramientas que un empleado dispone para elaborar su trabajo, los equipos utilizados, los procedimientos adecuados.

*Actualmente se conciben también las tecnologías de información y comunicaciones (TICs), las cuales han permitido implementar la automatización, en las empresas modernas, se cuenta con programas orientados a mejorar los procesos productivos los cuales llevan a las organizaciones a ser clasificadas como organizaciones de desarrollo tecnológico; dentro de éste último concepto, se encuentran las empresas de investigación y desarrollo tecnológico, las industrias productoras de software y las empresas de investigación y desarrollo científicos; Vr.Gr, la industria farmacéutica, que al ser sumadas estos dos campos de desarrollo del conocimiento en ámbito académico son identificadas como investigación en ciencia y tecnología con una fuerte interacción con los países 
ISSN-2248-736 * Número 3 * Revista Facta Non Verba

la cual estará representada por la ecuación Investigación y Desarrollo (I+D).

*El conocimiento artístico (arte). Se ocupa de la imitación de la realidad mediante expresiones plásticas, escénicas, sonoras, en la cual la estética, rige el deleite de los sentidos en la búsqueda constante por el placer sensorial y sensual. La estética procura el equilibrio humano de lo bello de las cosas.

Igualmente, el arte puede expresarse como lo bello de las acciones humanas. El trabajo humano y su actividad en general están cargados de valoraciones prestablecidas como bellas o su contrario. Las profesiones y oficios de las personas pueden ser consideradas arte por su alta carga de estética. El conocimiento artístico, se refleja en la estética de lo bello: es decir, en la forma de hacer las cosas."

Dentro de la organización no es suficiente que los trabajadores realicen sus tareas de manera eficiente se requiere además que sean realizadas bajo los principios de la estética ya que él forma parte de la valoración de la calidad en el trabajo, en el producto o en el servicio que ofrecen las empresas. (Marshall \& Warren, 1884).

Esa forma de hacer las cosas es la "Creatividad".

La creatividad simboliza la producción de algo nuevo, y este "algo nuevo" puede ser una solución novedosa o "una solución" resultante de la reformulación de un problema.

La creatividad y la innovación están a la base de la solución de problemas, lo que incluye también la innovación estratégica.

La imaginación, que comprende la generación de ideas antes no existentes, o la generación de diferentes modos de ver una situación, es importante para lograr acciones creativas.

Normalmente, la creatividad consiste en reconocer la relación antes no vista entre cosas (conceptos) produciendo algo nuevo, dando solución a un problema mediato o inmediato, explícito o latente. La creatividad es una característica de la inteligencia humana y es una función de nuestras capacidades más comunes, tales como la asociación de ideas, la memoria (o los recuerdos), la percepción, el pensamiento analógico, la búsqueda en el espacio de un problema estructurado y el pensamiento crítico. O la casualidad. La motivación y la emoción son indispensables.
El contexto cultural y algunos factores de la personalidad son también muy importantes.

La creatividad tiene lugar sobre los conceptos, sobre las ideas. Puede ser combinatoria, integrando atributos de ideas conocidas; exploratorias (investigativa), generando nuevas ideas a partir de la exploración de conceptos estructurados, o de transformación, lo que implica la transformación de alguna dimensión de la estructura conceptual, para crear nuevas estructuras.

La creatividad es la base de la innovación, son actividades complementarias. No existe la innovación sin ideas creativas. El pensamiento creativo organizado (aunque la creatividad es un don personal), la innovación, es el resultado de la creatividad en una cultura organizacional apropiada.

Es esta cultura corporativa lo que estimula y acoge, a través de las técnicas creativas, las posibilidades para el desarrollo de las habilidades creativas personales y de grupo. Las técnicas para la generación de la creatividad se implementan en la organización (empresa, entidad gubernamental, organización de gobierno, en el estudio técnico o de consultoría, en la universidad o escuela primaria o técnica.) En la organización moderna, el ejercicio organizado de la creatividad se convierte en un proceso estandarizado.

*El conocimiento intuitivo, es el que permite elaborar pronósticos, diagnostica lo que puede pasar basado en experiencias pasadas o vivencias anteriores. Fundamentalmente se basa en minimizar el nivel de incertidumbre y el margen de error, dimensiona el acierto (predictivos $o$ visionarios.

*El nivel de predicción se basa en los conocimientos teóricos o prácticos... de ninguna manera son fruto del azar, cuando se combinan todos estos elementos de manera ideal se denomina capital intelectual de las organizaciones. (Bradley, 1978)

"Por consiguiente, como acabamos de decir, el hombre de experiencia parece ser más sabio que el que sólo tiene 
conocimientos sensibles, cualesquiera que ellos sean: el hombre de arte lo es más que el hombre de experiencia; el operario es motivado por el director del trabajo, $y$ la especulación es superior a la práctica” (Kant, 2003)

Aristóteles rechaza explícitamente el conocimiento innato (innatismo), y no lo presenta como el resultado del aprendizaje, es decir, por la coordinación racional de los elementos procedentes de la sensación, a través de la experiencia. Coinciden Aristóteles, Platón y Descartes, en que para la aplicación del conocimiento científico o conocimiento técnico se recurre a lo universal, y no a los objetos singulares.

Se debe entonces definir qué se entiende por ¿tecnología?, la tecnología se define: "Como un saber científico, como una hipótesis comprobada empíricamente”, pero es más que un conocimiento aplicado. Los términos tecnología y ciencia son complementarios y presentan una relación muy estrecha. La tecnología acude a la ciencia para fundamentar y sustentar, y a su vez genera nuevos interrogantes, lo que se traduce en necesidades nuevas dentro de la sociedad, aquí se evidencia cómo la tecnología facilita la adecuación, transformación, el progreso, el cambio, el aprendizaje y la cultura del entorno, desarrollando instrumentos que permiten generar procesos transformadores e innovadores, esto se evidencia en el impacto que pueda tener dentro de todos los sectores de la sociedad.

Existen otras clasificaciones como las que presenta (McNamara \& Kirakowski, 2008) se pueden tipificar cinco tipos de conocimiento relacionados con el contenido semántico. Orientados a verlo desde la perspectiva de la Inteligencia Artificial AI.

\footnotetext{
*Conocimiento de procedimientos o conocimiento procedural. En la aplicación del entorno de la AI este tipo de conocimiento se constituye en un paradigma de cómo se hacen las cosas.
}

\section{*Conocimiento de objetos y hechos o conocimiento}

declarativo. Tiene que ver con el conocimiento sensorial, el cual permite tener la percepción del mundo externo a través de los sentidos y ubicar el propio yo en contexto.

* Conocimiento de consecuencias o conocimiento de razonamiento. Es el conocimiento que surge a partir de los procedimientos, del conocimiento del objeto y los hechos. Dentro del aprendizaje procedural y declarativo se basa el estudio por casos los cuales permiten la aplicación de los conocimientos en la AI.

*Conocimiento de definiciones. Tiene sus fundamentos en la epistemología, pues tiene que ver la descripción de las características y la estructura de las relaciones que existen entre los conceptos. Se considera entonces una definición valida de este conocimiento el expresado por Kirakowski (2008) ${ }^{6}$, este conocimiento se utiliza como recurso lingüístico lexicográfico para adquirir conocimiento de forma automatizada, extrayéndolo de las estructuras conceptuales. Así mismo, este conocimiento contribuye al modelado del conocimiento dando pautas para la organización de la macroestructura y de la microestructura del conocimiento de un dominio.

*Metaconocimiento. Es el conocimiento acerca del objeto que se pretende sistematizar, mediante la planeación y la aplicación del conocimiento bajo el entorno de un sistema. Este conocimiento contempla tanto el conocimiento de las definiciones, de los procedimientos, de objetos, y de los hechos que posee el sistema, dicho de otra manera es la contemplación del conocimiento implícito y del conocimiento explícito, utilizado en la ingeniería lingüística para desarrollar sistemas bajo la ingeniería del conocimiento.

La figura $\mathrm{N}^{\mathrm{o}} 1$ Ingeniería del conocimiento

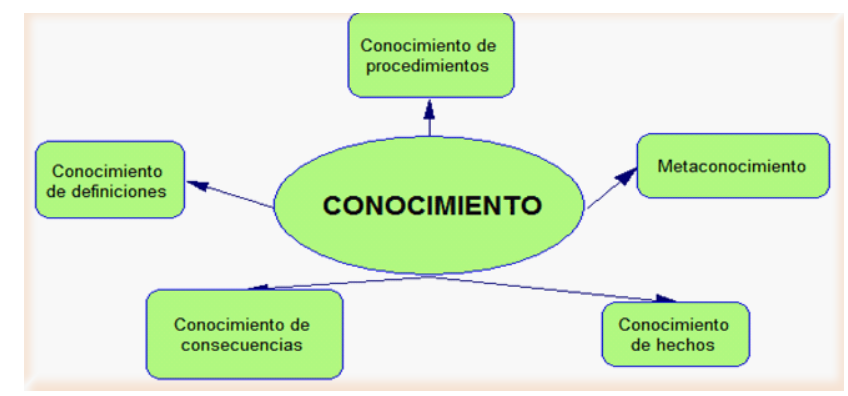

Fuente: (Cámara de la Fuente, 2004)

6 "Es el conocimiento articulado, elaborado, asentado, sintetizado y formulado derivado del conocimiento de procedimientos, de hechos y de consecuencias. Este tipo de conocimiento tiene fundamentos epistemológicos y se representa de forma textual mediante la descripción de sus características y la estructuración de las relaciones que existen entre los conceptos (estructuras conceptuales) que subyacen al texto de la definición. 
ISSN-2248-736 * Número 3 * Revista Facta Non Verba

La figura $\mathrm{N}^{\mathrm{o}} 1$ presenta los cinco grupos mediante los cuales se clasifica el conocimiento, pero es muy común encontrar diferentes tipos de conocimiento combinado. Al optar por la clasificación respecto a la transferencia encontraríamos dos categorías.

El conocimiento tácito "Es el saber que tiene un individuo u entidad compuesta de individuos. Este conocimiento responde a preguntas sobre cómo se hacen las cosas: cómo se resuelven problemas, cuándo resolverlos y de dónde se obtienen los recursos para poder solventarlos. Está orientado a la experiencia y tiene un motor consciente y otro inconsciente: por eso, es difícil hacerlo explícito en su totalidad.

Este saber engloba todas las habilidades que tienen las personas y se transfiere de manera informal.

Según (Reber, Toler, \& Perttunen, 1999), el término conocimiento tácito aparece por primera vez en dos obras de (Polanyi, 1958). Sin embargo, el concepto implícito en el término de proceso intelectual (cognitivo) y emocional (de conducta) con dos niveles de percepción, el consciente y el inconsciente, es una idea formulada por Lashley (1956, 1-18).”, (Kinsbourne, 2006)

Figura No. 2 Dificultad de transferencia de los niveles de conocimiento

\begin{tabular}{l|c|c} 
& COGNITIVO & EMOCIONAL \\
\hline CONSCIENTE & Fácil & -- Difícil \\
\hline INCONSCIENTE & Difícil & MLy dificil \\
\hline
\end{tabular}

Fuente: (Cámara de la Fuente,2004)

El conocimiento explícito, también llamado conocimiento convencional, es aquél que ya está representado o documentado y se utiliza como medio para transmitir los procedimientos que se han que seguir para resolver de forma óptima cualquier trabajo, problema o proceso, en general. Por tanto, este conocimiento está orientado conscientemente a la resolución de problemas y se haya siempre representado, lo que supone poder acceder a él conscientemente. Todo el conocimiento representado es conocimiento explícito y se genera a partir de conocimiento tácito o de conocimiento previo explícito. Esta representación del conocimiento es la interfaz entre el cerebro y el mundo exterior.

El conocimiento representado, se convierte en producto tangible, con respecto al conocimiento que se crea, se infiere, se interpreta, se deduce, se desprende, se dilucida, y que engloba el conocimiento tácito. Más adelante se explica de qué formas y mediante qué recursos se puede representar el conocimiento representado.

El conocimiento que no es representado y, por tanto, no es explícito es un proceso difícil de medir debido a su intangibilidad. La representación del saber puede someterse a un modelado relativo, es decir, se puede partir de términos, estructuras conceptuales comunes o procedimientos que ayuden a codificar el conocimiento para desarrollar y gestionar de forma más eficiente el conocimiento individual y colectivo. Otro término que identifica el mismo concepto englobado en gestión de conocimiento explícito y es gestión de contenidos. Aquí para los propósitos del texto, se utilizará indistintamente ambos términos.

\subsection{De la información al conocimiento}

Desde la aplicación sistemática de la tecnología para procesar información, una de las definiciones más extendidas de información es la aportada por Shannon y Weaver (1963), padres de la teoría de la información que más peso ha tenido en los últimos años. Para éstos, el concepto información es un producto vinculado a la cantidad de datos de un mensaje y, por tanto, tiene un enfoque estadístico. La información es, además, un proceso secuencial identificable con un paradigma lineal subyacente. El contenido de la información, el mensaje codificado, tiene, pues, un emisor y un receptor, se transmiten a través de un canal y está incluido en un contexto.

Tabla No. 3 Modelo de Shannon y Weaver para la comunicación de información

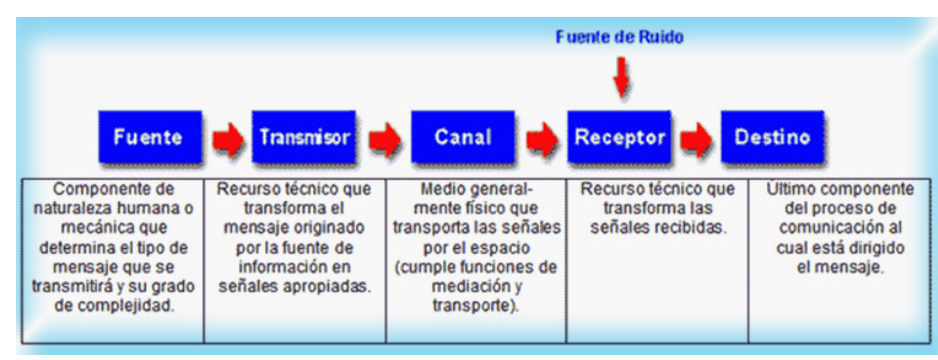

Fuente: (Cámara de la Fuente, 2004) 
En la presentación anterior Lidia Cámara esquematiza el modelo de información de Shannon y Weaver, como producto de la generación y transmisión lineal de datos codificados y representados de manera simbólica.

El conocimiento como se presentó al inicio de éste capítulo es todo aquello que es susceptible percibirse del mundo real o ficticio. "Desde el punto de vista neurocientífico, para que haya conocimiento, basta con que se activen las neuronas y desarrollen las relaciones sinápticas que generan a su vez posibles relaciones semánticas". En virtud de la simultaneidad de relaciones que pueden presentarse en las diferentes zonas del encéfalo, se da una actividad no lineal en donde puede variar en función del contexto, la percepción individual y social del agente (Kandel, Chen, Warner, Kessler, \& Grant, 1997). Diferencia entre el conocimiento humano y el conocimiento que puede procesarse mediante computadores, el primero llamado bio-conocimiento que es el producto dinámico de un proceso neuronal no lineal donde se involucra un gran número de variables que dificultan su gestión.

La gestión empresarial del conocimiento (gestión organizativa), se basa en la integración de un cuerpo de verdades, principios e información que en el marco de los negocios guía las operaciones del mismo (Bassie, Noury, Lepri, Lahaye, Christou, \& Capell, 2000). Al analizar esta definición como guía de tareas relacionadas, se encuentra que también involucra la gestión de la información, convirtiéndose en el eje dinámico que pude influir en el objeto respecto a los procesos del agente en el contexto de la organización.

Separar información de conocimiento depende fundamentalmente de la variable tangible e intangible, recibida en forma de mensaje por parte del receptor el cual desarrolla un progreso cognitivo que tiene que ver con el caudal de información relevante y la información de predominio, por lo tanto, no solo tiene que ver con la percepción de la información del receptor sino el instante que el agente la interprete, para algunos autores quien decide que es realmente información depende del receptor y no del emisor, un ejemplo se da mediante: "Un informe lleno de tablas con símbolos donde no exista una leyenda puede ser considerado información que representa conocimiento por quien lo escribe, pero, a su vez, puede ser juzgado como ruido por el receptor, porque no es capaz de interpretar lo que recibe".

En el ámbito de la semántica léxica y computacional, (Díez \& Berjano, 1999), hace la distinción entre conocimiento y razonamiento: "Además, tenemos que distinguir también entre conocimiento y razonamiento, ya que el primero está ligado a los sistemas de representación y almacenamiento de la información y el segundo a la recuperación, conexión e inferencias y cálculos hechos con esa información (motores de inferencia), creando información nueva. A priori, cualquier sistema de representación del conocimiento ha de servir para realizar tareas de razonamiento.

La distinción de Díez es aplicable a los entornos de la ingeniería del conocimiento, en los que el conocimiento se concibe entonces como la información preparada para que los motores de inferencia puedan "razonar" $y$, por lo tanto, el resultado sería un razonamiento.

Nosotros seguiremos llamando conocimiento también al razonamiento en el contexto de una aplicación o un sistema, puesto que, concretamente en el proceso del acceso a la información, ésta se convierte en conocimiento si el acto comunicativo a través de una interfaz es satisfactorio para el usuario o receptor, responsable de la primera parte de la emisión del mensaje, en forma de entrada de datos al sistema de acceso a la información y, por último, responsable también de la satisfacción obtenida, con independencia del proceso inferencial que haya realizado el sistema. El sistema de información interactúa como receptor y emisor con el humano ofreciéndole una respuesta al humano (emisor y receptor) que siempre está supeditada al mensaje introducido, sin tener en cuenta el contexto".

Los datos, la información, y el conocimiento para nuestros fines son inseparables; además son elementos fundamentales en el procesamiento cognitivo humano denominado gestión del conocimiento, como lo enuncia Cornella "La metabolización de la información, su conversión en estructuras mentales, generalmente permanentes, lleva a la creación de conocimiento en nuestras mentes. Así si un determinado contexto nos lleva a interpretar los datos de una determinada manera, en ese acto hemos creado información. La combinación de esa información con otras informaciones no puede llevar a crear un modelo de interpretación (reflexión y análisis), nos permite llegar a conclusiones (sintesis), hace que nos surjan ideas nuevas (abstracción), de manera que puede decirse que hay un antes y un después de nuestro estado mental." (Cornella, 2000).

Desde el concepto de información y ciencia se da bajo la siguiente exposición "Está claro que se puede creer en algo, sin ninguna justificación, por ejemplo, sí se construye un edificio sin bases sólidas, a pesar que se crea que va a soportar el peso, no lo hará. Para determinar la validez de esta idea, se debe en tanto ofrecer una justificación mediante la evaluación racional que permita respaldar esa creencia, es decir comparar la evidencia a favor con la evidencia en contra. Para lo cual hay dos 


\section{ISSN-2248-736 * Número 3 * Revista Facta Non Verba}

caminos, el Coherentismo, donde no hay hechos que respalden la explicación, sino otra creencia, y donde cada creencia se apoya entre sí. Esta justificación es propia de las religiones" (Dretske, 1981)

Por otra parte, el Fundacionalismo, que apela a los hechos o a la razón como fundamento de la creencia. "La creencia verdadera justificada en últimas, explica el concepto de verdad, que es verdad?, toda ;creencia verdadera justificada!, por tanto, la verdad como fundamento del conocimiento adquiere condición de provisionalidad, dado que mientras no exista una teoría que rebata a la otra, con suficiente justificación verdadera de un objeto, lo que se cree de éste: seguirá siendo verdad. Ahora bien, en la Organización no se requiere de este debate, pero sí de su comprensión, dado que la estructura mental de los miembros de la organización gira en torno a estos dos sentidos. Lo importante sería comprender que el conocimiento con suficiente evidencia y comprensión debe ser el capital intangible que permite operar a la empresa". (Brookings, Wilson, \& Swain, 1996)

Es así como se plantean dos problemas: el primero como lograr que los empleados busquen desde sus propios objetivos y creencias los objetivos corporativos, y el segundo es como lograr que los conocimientos teóricos, prácticos, técnicos, artísticos e intuitivos de los empleados jueguen con los objetivos de las organizaciones, dicho de otra manera son los activos intangibles, que se convierten en capitales intelectuales y éstos en patrimonio intelectual de las organizaciones.

Las organizaciones se abocan a resolver problemas en la producción del conocimiento, que no puede dejar a libre albedrio de los empleados sino que debe llegar a la planeación del conocimiento bajo unidades de investigación e innovación con gran soporte tecnológico que potencialice el transporte y la circulación del conocimiento y carreras profesionales.

\subsection{Tareas de la gestión del conocimiento}

En la administración y dirección de empresas se ha incorporado como asignatura lo que ha llevado a pensar que es algo nuevo, sin embargo, se conoce como gestión de aprendizaje, y transferencia del saber, la gestión del conocimiento es un concepto que aglutina la generación, la representación, la adquisición, en cuanto a las tareas vinculadas con la gestión del conocimiento son relativamente recientes.

En este sentido, las universidades y cualquier centro de formación son centros de gestión del conocimiento por tener como objetivo la generación y la transferencia del saber, en beneficio de la adquisición de ese mismo saber. Sin ir más lejos, los seminarios, cursos, conferencias son modelos de transferencia de conocimiento.
Así mismo, desde su origen, las bibliotecas están concebidas para almacenar y clasificar conocimiento explícito para facilitar su transferencia. Las bibliotecas y cualquier centro de documentación gestionan el conocimiento una vez que está representado, es decir, cuando ya se ha convertido en texto, imagen o sonido, o en alguna combinación de tales elementos.

\section{Bibliografía}

*Bassie, 1., Noury, M., Lepri, O., Lahaye, T., Christou, P., \& Capell, T. (2000). La fuerza del promotor influye en el metabolismo de poliaminas y la capacidad morfogénica en los tejiilos de arroz transgénicas que expresan elADNc de avenaADC constitutivam. Transgenic Research, 9(1), 33-42.

*Bradley, G. (1978). Auto-servicio de sesgos en el proceso de atribución:. Un nuevo examen del hecho o cuestión de ficción Diario de la personalidad y la psicología social , 36(1), 56.

*Brookings, J., Wilson, G., \& Swain, C. (1996). Respuestas psicofisiológicas a los cambios en la carga de trabajo durante el control del tráfico aéreo simulado. Biological Psychology , 42 (3), 361-377.

*Cámara de la Fuente, L. (2004). La representación lingüística del conocimiento y su relevancia en la ingeniería lingüística. Hipertext. net, (2).

*Comella, A. (2000). Cómo sobrevivir a la infoxicación. Infonomia. com, 8.

*Díez, J., \& Berjano, E. (1999). El consumo abusivo de alcohol en la adolescencia: un modelo explicativo desde la psicología social.

*Dretske, F. (1981). El conocimiento y el flujo de información.

*Drucker, P.(1992). Dirección de Instituciones pecado multas de Lucro. Teoría y Práctica. Gestión de la organización sin ánimo de lucro. . Biblioteca de Ciencias Económicas. : Serie: Dirección de Empresas (Argentina).

*Grayling, A. C. (1998). Philosophy 2: Further through the subject. . Oxford University Press.

*Habermas, J. (1989). “Modemidad un proyecto incompleto", aparecido en El debate sobre modernidad posmodemidad, 1989, E. Puntosur, pag 143. E. Puntosur.

*Habermas, J., Borradori, G., \& Derrida, J. (2004). Habermas, J., Borradori, G., y Derrida, J. (2004). Filosofia en una época de terror: Diálogos con Jürgen Habermas y Jacques Derrida . Chicago: University of Chicago Press.

*Heidegger, M. (1994). La pregunta por la técnica. Conferencias y artículos, 5.

*Hessen, J. (1970). Teoría del conocimiento. Espasa-Calpe.

*Kandel, D., Chen, K., Wamer, L., Kessler, K., \& Grant, B. (1997). Prevalencia y correlatos demográficos de los síntomas de la última dependencia de año sobre el alcohol, la nicotina, la marihuana y la cocaína en la población de EE.UU.. drogas y la dependencia del alcohol , 44(1), 11-29.

*Kant, I.(2003). Fundamentación de lametafisica de las costumbres(Vol. 18). . Ediciones Encuentro Sa. *Kinsbourne, M. (2006). Desde el abandono unilateral de las bases cerebrales de la conciencia. Corteza, 42 (6), 869-874.

*Marshall, B., \& Warren, J. (1884). Bacilos curvados no identificados en el estómago de pacientes con gastritis yúlcera péptica. The Lancet, 323 (8390),, 1311-1315.

*McNamara, N., \& Kirakowski, J.(2008). (2008). Medición del factor humano en las tecnologías complejas. Revista Internacional de Tecnología e Interacción Humana (IJTHI), 4(1), 1-14.

*Medina, A., González,A., \& Falcón, J. (2007). (2007). El concepto del capital intelectual y sus dimensiones. Investigaciones europeas de dirección y economía de la empresa, 13(2), 97-112. *Polanyi, M. (1958). El estudio del hombre. Universidad de Chicago.

*Reber, W., Toler, J., \& Perttunen, C. (1999). Patente de EE.UU. N ${ }^{\circ} 5.961 .451$. Washington, DC:: Oficina de Marcas y Patentes de EE.UU..

*Sveiby, K., Linard, K., \& Dvorsky, L. (2002). Building a knowledge-based strategy: A system dynamics model for allocating value adding capacity. Sveiby Knowledge Associates.

*Torralba, J. M. (2005). Acción intencional y razonamiento práctico. Pamplona: Eunsa. *Vattimo, G. ( 1990). La sociedad transparente. Barcelona, México: Paidós. 